\title{
The Effects of the Roy's Adaptation Model on Primigravida Women's Self-Concept: A Randomized Controlled Trial
}

\author{
Ali Mohammadpour', Samane Najafi ${ }^{2,3^{*}}$, Jahanshir Tavakkolizadeh ${ }^{4}$ \\ and Fatemeh Mohammadzadeh ${ }^{5}$ \\ 'Department of Medical-Surgical Nursing, Faculty of Nursing and Midwifery, Social Determinants of Health \\ Research Center, Gonabad University of Medical Sciences, Gonabad, Iran \\ 2Department of Medical-Surgical Nursing, Faculty of Nursing and Midwifery, Social Development \\ and Health Promotion Research Center, Gonabad University of Medical Sciences, Gonabad, Iran \\ ${ }^{3}$ Department of Family Health, Social Development and Health Promotion Research Center, \\ Gonabad University of Medical Sciences, Gonabad, Iran; S.Najafi2012@yahoo.com \\ ${ }^{4}$ Department of Clinical Psychology, Gonabad University of Medical Sciences, Gonabad, Iran \\ ${ }^{5}$ Department of Basic Sciences, Gonabad University of Medical Sciences, Gonabad, Iran
}

\begin{abstract}
Most women do not have a positive self-concept and impression about themselves during pregnancy because they become less active and gain more weight. Self-concept significantly contributes to individuals' mental health. This controlled trial was performed to assess the effect of an intervention based on the Roy's adaptation model on self-concept among primigravida women. This study was conducted on a random sample of 83 Iranian primigravida women. Women in the experimental group received educational and counseling services in five sessions held in five consecutive weeks. Thereafter, they received a four-week follow-up care. Before the intervention, there were no significant differences between the two groups regarding adaptation knowledge and self-concept adaptation. However, after the intervention, these differences were statistically significant. The Roy's adaptation model has positive effects on primigravida women's physical and interpersonal self-concept adaptation. Given its simplicity and easy applicability, this model can be used for improving pregnancy-related outcomes.
\end{abstract}

Keywords: Primigravida Women, Physical and Interpersonal Self-Concept, Roy's Adaptation Model

\section{Introduction}

Pregnancy is a unique situation which is associated with extensive physiological and psychological changes ${ }^{1}$. Changes in appearance prevent many pregnant women from having a positive self-image ${ }^{2}$. Besides changes in appearance, most pregnant women also experience difficulties in communicating with others. In other words, women's physical self and interpersonal self deteriorate during pregnancy. These problems inflict psychological damage on pregnant women, particularly during their first pregnancy ${ }^{1}$. Psychological damage, in turn, is associated with different complications such as heightened risks for prematurity, preterm birth, and cardiovascular disease later in life 3 .

Providing quality care and educations to pregnant women can promote their adaptation to pregnancyinduced changes 4 . Pregnant women's attendance at healthcare settings provides healthcare professionals with excellent opportunities for delivering psychological care and educations to them. However, in our country, Iran, healthcare professionals pay little attention to psychological care delivery to pregnant women ${ }^{5}$. The current pregnancy care programs which are offered in

${ }^{*}$ Author for correspondence 
Iranian health care settings mainly focus on pregnant women's physiological problems and needs while taking psychological aspects of pregnancy care for granted.

One of the practical care delivery models which mainly focus on promoting individuals' adaptation in unique, high-pressure situations such as pregnancy is the Roy's adaptation model (RAM) ${ }^{6}$. This model can be employed by healthcare professionals for promoting pregnant women's adaptation to pregnancy-related problems ${ }^{7}$. According to the RAM, adaptation is a set of processes through which an individual responds to environmental changes or stimuli. The aim of nursing interventions in the RAM is to enhance adaptive responses in each of the four physiological, self-concept, interdependence, and role function modes. As one of the adaptive modes in the RAM, self-concept is defined as individuals' feelings about oneself and is influenced by many factors chiefly others' reactions. Self-concept consists of three components including physical self, personal self, and interpersonal self. Physical self is an individual's perception of his/ her own body while interpersonal self is an individual's perception in relation with others ${ }^{8}$. The RAM, particularly assesses and focuses on the self-concept mode and pays a special attention to it.

Other key concepts of the RAM are focal stimulus, contextual stimuli, and residual stimuli. Focal stimulus is a stimulus which directly affects individual and has the greatest role in his/her ineffective adaptation. Contextual stimuli are not as immediate as the focal stimulus, but may negatively affect it. Residual stimuli relate to individual's personal traits, experiences, and beliefs and their effects on the immediate situation are not obvious ${ }^{9}$.

Previous studies have shown the effectiveness of the RAM in promoting clients' adaptation ${ }^{10-13}$. However, to the best of our knowledge, only a few studies have investigated the effects of the RAM on women's adaptation to pregnancyrelated problems, particularly problems with selfconcept. The aim of this study is to investigate the effects of an intervention based on the RAM on physical and interpersonal components of self-concept.

\section{Materials and Methods}

\subsection{Study Design, Setting and Samples}

This was a randomized controlled field trial. All primigravida women who referred to public outpatient health centers located in Gonabad, Iran, were approached. The simple random sampling method was used to select a random sample of 83 primigravida women. Participants were allocated to either the control or the experimental groups by using the permuted block randomization technique. The size of the blocks was equal to four. Considering an $\alpha$ of 0.05 , a $\beta$ of 0.2 , a $S 1$ of 5.7 , a S2 of 5.0, a $\mu_{1}$ of 22.5 , and a $\mu_{2}$ of 18.85 , the sample size calculation formula (Figure 1) showed that 34 women in each group were needed for the study. Given the likelihood of dropouts during the study, we recruited 44 women to each group. Five participants were excluded due to having preterm labor, developing pre-eclampsia or premature rupture of membrane, or poor attendance in our educational sessions. The inclusion criteria were primigravida, being at the 24th-28th weeks of pregnancy, having no pregnancy-related complications such as eclampsia, preeclampsia, and gestational diabetes mellitus, having no history of the known psychological disorder, having received no education or care regarding self-concept, being able to read and write Persian, and living with husband. Patients were excluded if they developed any of the aforementioned pregnancy complications, went into a preterm labor during the study, opted for withdrawing from the study, and had inactive participation in our educations.

$n=\left(\left(Z_{1-\alpha / 2}+Z_{1-\beta}\right)^{2} \times\left(S_{1}^{2}+S_{2}^{2}\right)\right) /\left(\mu_{1}-\mu_{2}\right)^{2}=\left(7.84 \times\left(5.7^{2}+5.0^{2}\right)\right) /(22.5-18.85)^{2}=34$

\subsection{Measurements and Instruments}

The data collection tool comprised three parts. The first part consisted of items on participants' demographic characteristics. The second part consisted of eighteen multiple-choice questions relating to participants' knowledge about how to manage pregnancy complications and problems. The third part of the study data collection tool was a researcher-made Self-concept Adaptation Scale (SAS). We developed the SAS based on the RAM and used it for assessing the participating women's self-concept adaptation. The SAS consists of 27 items in two main domains, including physical self-concept (thirteen items) and interpersonal self-concept (fourteen items). Items are scored on a Likert scale from 1 (Never) to 4 (Very much). Higher scores show lower levels of adaptation. Ten experts in obstetrics and gynecology, nursing, instrument development, and RAM application were asked to evaluate the content validity of the questionnaire. The reliability of the scale was assessed by using the test-retest and the 
Cronbach's alpha methods. In the test-retest reliability assessment method, ten primigravida women were invited to complete the SAS twice with a two-week interval in between. The Pearson correlation coefficient between the two readings was 0.88 . Moreover, we administered the scale to forty pregnant women for the purpose of internal consistency assessment. The Cronbach's alpha was equal to 0.86 .

\subsection{Data Collection and Procedure}

Initially, patients' maladaptive behaviors and corresponding focal, contextual, and residual stimuli were identified and prioritized by using the study questionnaire as well as through conducting personal face-to-face interviews with the participants. The study participants' maladaptive behaviors in the area of physical and interpersonal self-concept included disturbed body image, fear, low self-confidence, grief, sexual dysfunction, disturbed marital relationships, and impaired social interactions. The stimuli contributing to these maladaptive behaviors were a lack of knowledge related to pregnancyinduced changes in physiological and psychological changes, husbands' lack of knowledge about the process of pregnancy and the associating physiological changes, pregnancy-induced restrictions, and fear over one's own as well as baby's health. Accordingly, an intervention program was developed by using the RAM for eliminating or modifying the focal stimulus as well as for minimizing

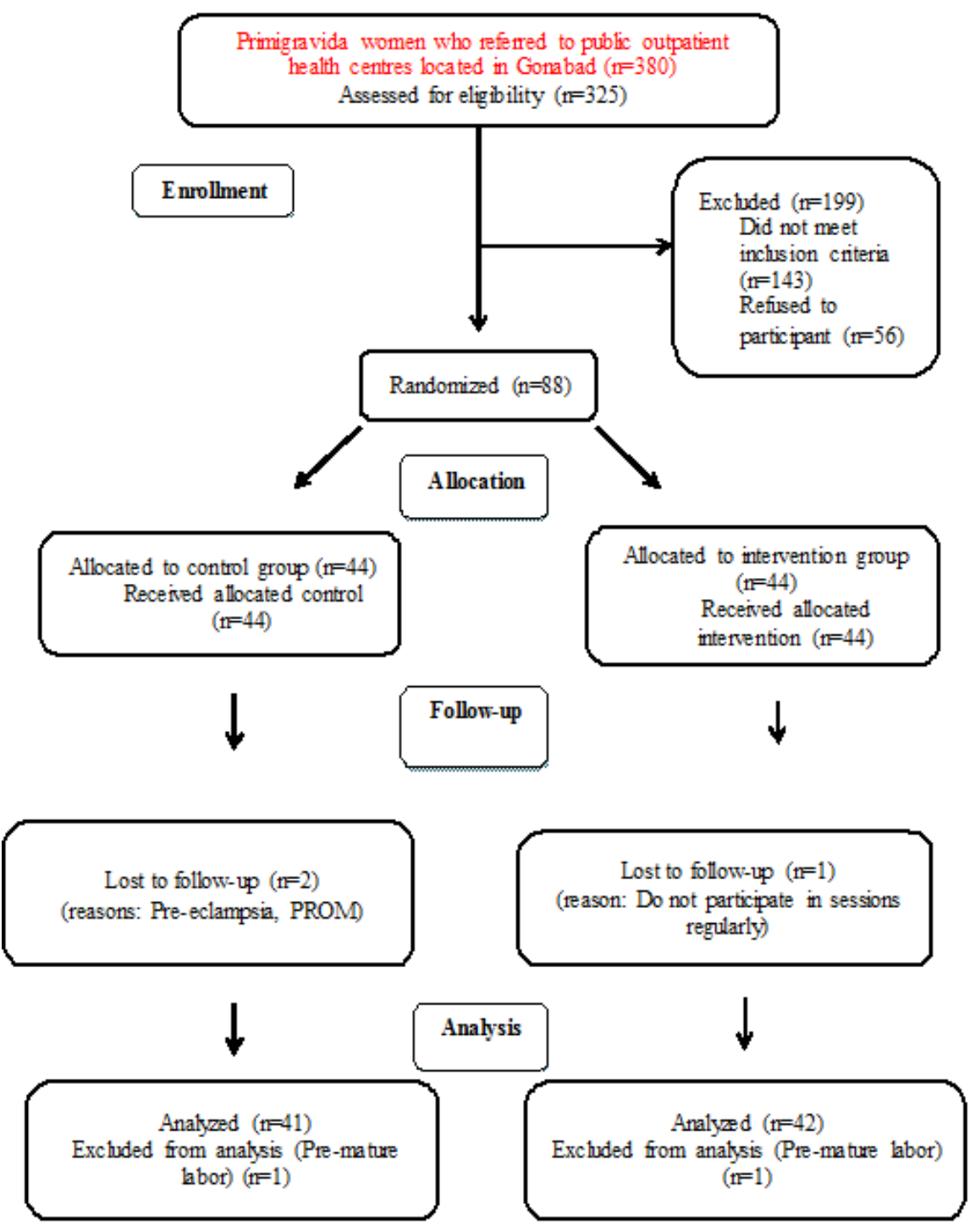

Figure 1. Flow of participants through each stage of this study. 
the effects of contextual and residual stimuli through enhancing participants' adaptation capacity. The programs consisted of educational and counseling services provided by a nurse (two sessions) and a mental health counselor (three sessions). The contents of counseling sessions included of strategies for effective communication with others and one's own husband, happy life skills, stress and anger management skills, and encouragement for pregnant women to express their feelings about pregnancy and labor. On the other hand, the educational content was comprised of materials on common pregnancy-related complaints and how to manage them, the role of stress in pregnancy and its effects on mother and baby's health, physical health during pregnancy, physical exercise and fitness during pregnancy, effective interpersonal communication and marital relationship skills. These educational and counseling services were provided only to women in the experimental group in five 90-minute sessions which were held in five consecutive weeks. Each session consisted of a 60-minute lecture and a subsequent 30-minute group discussion for answering participants' questions. The course of the study intervention lasted for nine consecutive weeks-five weeks for implementing the intervention and manipulating the stimuli and four weeks for providing support and follow-up care. The follow-up care consisted of face-to-face and telephone contacts for answering participants' questions and promoting their adherence to the delivered educations and counseling. Women in both groups also received routine pregnancy care. Finally, all the study participants were invited to complete the posttest (Figure 1). After conducting the posttest, patients in the control group also received the educational and counseling services in the form of an educational package.

\subsection{Ethical Considerations}

The Research Ethics Committee of Gonabad University of Medical Sciences, Gonabad, Iran, approved the study (GMU.REC.1393.7). Moreover, the Iranian Registry of Clinical Trials registered the study (IRCT2014052217800N1). Necessary permissions were also obtained from the administrators of the affiliated health centers. Study participants were assured that they were free to withdraw from the study and that their information would be handled confidentially. Moreover, they were informed that they would be allocated to one of the study groups on a random basis. Written informed consent was obtained from each of them. After the study, women in the control group were provided with a written educational package containing the educations which had been provided to women in the experimental group.

\subsection{Data Analysis}

The SPSS software (v. 21.0) was used for managing and summarizing the data and conducting statistical tests such as paired- and independent-samples $t$, Chi-square, Mann-Whitney, Wilcoxon signed-rank, Pearson and Spearman correlation, and one-way analysis of variance (ANOVA). P-values which were less than 0.05 were considered as significant.

Table 1. Demographic characteristics in both groups $(n=83)$

\begin{tabular}{lccc}
\hline Demographic Characteristics & $\begin{array}{c}\text { Experimen- } \\
\text { tal Group }\end{array}$ & $\begin{array}{c}\text { Control } \\
\text { Group }\end{array}$ & $\begin{array}{c}\text { Statistical } \\
\text { Test Results }\end{array}$ \\
\hline Age, Mean (SD), y & $23.95(3.29)$ & $25.05(4.71)$ & $\mathrm{t}=1.23$ \\
& & & $\mathrm{P}=.22$ \\
Education, $\mathrm{n}(\%)^{\mathrm{a}}$ & $3(7.14)$ & $1(2.43)$ & \\
Elementary & $1(2.38)$ & $0(.00)$ & $\mathrm{x}^{2}=4.18$ \\
Guidance & $11(26.19)$ & $18(43.90)$ & $\mathrm{P}=.24$ \\
High School & $27(64.29)$ & $22(53.67)$ & \\
Academic & $39(92.85)$ & $33(80.48)$ & $\mathrm{x}^{2}=2.76$ \\
Occurrence of Pregnancy, $\mathrm{n}(\%)^{\mathrm{a}}$ & $3(7.15)$ & $8(19.25)$ & $\mathrm{P}=.09$ \\
Wanted & & & \\
Unwanted & $2(4.76)$ & $4(9.75)$ & $\mathrm{x}^{2}=0.77$ \\
use of assisted reproductive technology, $\mathrm{n}(\%)^{\mathrm{a}}$ & $\mathrm{P}=.38$ \\
Yes & $40(95.24)$ & $37(90.25)$ & \\
No & & & \\
${ }^{\mathrm{a} D a t a}$ available for 83 participants & & & \\
& &
\end{tabular}


Table 2. Self-concept adaptation in both groups before and after the study

\begin{tabular}{|c|c|c|c|c|c|c|c|}
\hline \multirow{3}{*}{$\begin{array}{l}\text { Self-concept } \\
\text { Components }\end{array}$} & \multirow{3}{*}{$\begin{array}{l}\text { Study } \\
\text { Phase }\end{array}$} & \multirow[t]{3}{*}{ Groups } & \multirow{3}{*}{$\begin{array}{l}\text { Adaptation } \\
\text { Scores, } \\
\text { Mean (SD) }\end{array}$} & \multicolumn{2}{|c|}{ Between Groups } & \multirow{2}{*}{\multicolumn{2}{|c|}{$\begin{array}{c}\text { Within Groups } \\
\text { Statistical Test (P-Value) }\end{array}$}} \\
\hline & & & & \multirow[t]{2}{*}{ Statistical Test } & \multirow[t]{2}{*}{ P-Value } & & \\
\hline & & & & & & $\begin{array}{l}\text { Experimental } \\
\text { Group }\end{array}$ & Control Group \\
\hline \multirow[t]{4}{*}{ Physical Self } & \multirow[t]{2}{*}{ Before } & Experimental & $24.55(4.32)$ & \multirow[t]{2}{*}{ Independent-Samples t } & \multirow[t]{2}{*}{$\mathrm{P}=.61$} & \multirow{4}{*}{$\begin{array}{l}\text { paired-samples t } \\
(\mathrm{P}<.001)^{*}\end{array}$} & \multirow{4}{*}{$\begin{array}{l}\text { paired-samples t } \\
(\mathrm{P}=.01)^{*}\end{array}$} \\
\hline & & Control & $25(3.80)$ & & & & \\
\hline & \multirow[t]{2}{*}{ After } & Experimental & $18.50(2.97)$ & \multirow[t]{2}{*}{ Independent-Samples t } & \multirow[t]{2}{*}{$\mathrm{P}<.001^{*}$} & & \\
\hline & & Control & $25.48(4.11)$ & & & & \\
\hline \multirow{4}{*}{$\begin{array}{l}\text { Interpersonal } \\
\text { Self }\end{array}$} & \multirow[t]{2}{*}{ Before } & Experimental & $19.55(4.60)$ & \multirow[t]{2}{*}{ Independent-Samples $t$} & \multirow[t]{2}{*}{$\mathrm{P}=.16$} & \multirow{4}{*}{$\begin{array}{l}\text { paired-samples } \mathrm{t} \\
(\mathrm{P}<.001)^{*}\end{array}$} & \multirow{4}{*}{$\begin{array}{l}\text { Wilcoxon signed- } \\
\text { rank }(\mathrm{P}=.01)^{*}\end{array}$} \\
\hline & & Control & $21.12(5.51)$ & & & & \\
\hline & \multirow[t]{2}{*}{ After } & Experimental & $17.26(2.65)$ & \multirow[t]{2}{*}{ Mann-Whitney } & \multirow[t]{2}{*}{$\mathrm{P}<.001^{*}$} & & \\
\hline & & Control & $21.54(5.55)$ & & & & \\
\hline \multirow{4}{*}{$\begin{array}{l}\text { Self-concept } \\
\text { Mode }\end{array}$} & \multirow[t]{2}{*}{ Before } & Experimental & $44.10(8.92)$ & \multirow[t]{2}{*}{ Independent-Samples t } & \multirow[t]{2}{*}{$\mathrm{P}=.16$} & \multirow{4}{*}{$\begin{array}{l}\text { paired-samples } \mathrm{t} \\
(\mathrm{P}<.001)^{*}\end{array}$} & \multirow{4}{*}{$\begin{array}{l}\text { paired-samples t } \\
(\mathrm{P}<.001)^{*}\end{array}$} \\
\hline & & Control & $46.12(9.31)$ & & & & \\
\hline & \multirow[t]{2}{*}{ After } & Experimental & $35.76(5.62)$ & \multirow[t]{2}{*}{ Independent-Samples t } & \multirow[t]{2}{*}{$\mathrm{P}<.001^{*}$} & & \\
\hline & & Control & $47.02(9.66)$ & & & & \\
\hline
\end{tabular}

\section{Results and Discussion}

Before and after the study, participants ranged in gestational age from 24 to 28 and from 33 to 37 weeks, respectively. Most of the participants were housewives (68 women). The length of most of the participants' marital lives (73\%) was less than five years. The means of their husbands' ages were $27.98 \pm 2.50$ and $30.37 \pm 6.07$ respectively in the experimental and control groups. Most of the participants (71 women) reported that their family income was sufficient. The most common physical problems experienced by them were respectively edema in the face and the extremities, hyperpigmentation, back pain, and breast enlargement. Respectively $61.4 \%$ and $54.4 \%$ of the participants had not received educations about the causes of and strategies for managing pregnancy-related problems. The most important source for acquiring information about pregnancy $(20.5 \%)$ was the mass media (including radio, TV, books, magazines, newspapers, and internet websites). The independentsamples $t$ and the Chi-square tests revealed that the study groups did not differ significantly regarding demographic characteristics (Table 1).

The results of the independent-samples t-test indicated that the difference between the study groups regarding pretest readings of knowledge about managing pregnancy complications and problems $(\mathrm{P}$-value $=0.16)$. However, this difference was statistically significant after the study (P-value < 0.001). The results of the Wilcoxon signedranked test showed that posttest readings of physical, interpersonal, and total self-concepts in the experimental and the control groups were respectively lower and higher than the pretest readings. In other words, while self-concept scores in the control group increased, these scores in the experimental group decreased significantly after the study (P-value < 0.01; Table 2). Moreover, the independent-samples $\mathrm{t}$-test showed that there were no significant differences between the two groups regarding pretest readings of physical, interpersonal, and total self-concept. However, the posttest scores of physical, interpersonal, and total self-concept of the experimental group were significantly lower than the control group (P-value $<0.001 ;$ Table 2). The one-way ANOVA test showed that there was a significant difference among women with different income levels regarding the scores of self-concept adaptation (P-value $=0.03$ ). In other words, women with lower income acquired higher SAS scores. The Spearman correlation test also revealed that there was no significant correlation between participants' adaptation and their knowledge of managing pregnancyrelated complications and problems (P-value $>0.05)$.

This study investigated the effects of an intervention based on the RAM on physical and interpersonal components of self-concept among primigravida women. Study findings revealed that before starting the study intervention, women's self-concept adaptation was poor. Nakamura et al. also found that Japanese pre-labor hospitalized women, particularly primigravida women, had poor psychological adaptation to pregnancy and low readiness for labor ${ }^{14}$. Kiehl and White also found that women who had higher maternal adaptation felt greater self-confidence about their coping with postpartum 
maternal roles and were more satisfied with their lives and pregnancies. Moreover, they reported that greater adaptation to pregnancy was associated with greater readiness for labor and stronger marital relationship ${ }^{15}$.

We also found that the study intervention significantly promoted women's self-concept adaptation. Salari et al. and Barlow et al. also reported the same finding ${ }^{16,17}$. Sercekus and Mete found that antenatal educations significantly affected pregnant women's adaptation to pregnancy ${ }^{18}$. Malekpoor et al. also noted that educations and support help women adapt to and accept the realities and establish effective interpersonal communications and hence, decrease their psychological strains ${ }^{19}$. Moreover, Mangeli et al. found that educating pregnant women about common pregnancy-induced changes and strategies for coping with them significantly enhanced their satisfaction with marital life ${ }^{20}$. However, Hamilton et al. found that their one-month maternal preparation program had no significant effect on women's adaptation to pregnancy ${ }^{21}$. This conflicting finding can be attributed to the fact that compared with our nine-week intervention, Hamilton et al. implemented their intervention in a shorter period of time (four weeks) on both primigravida and multigravida women. Other studies have also shown the effectiveness of the RAM in improving adaptation among patients with other conditions such as breast cancer, diabetes mellitus, chest pain, heart failure, and age-related problems ${ }^{22-26}$.

\section{Conclusion}

The RAM has positive effects on primigravida women's physical and interpersonal self-concept adaptation to pregnancy and its associated problems. Given its simplicity and easy applicability, the RAM can be used for improving pregnancy-related outcomes. Accordingly, the RAM needs to be integrated into neonatal nursing curricula. Considering the paucity of studies on the effects of the RAM on primigravida women's adaptation to pregnancy, further studies are needed for providing decisive evidence in this area.

\section{Acknowledgements}

This article was extracted from the MSc nursing thesis by Samane Najafi in the Gonabad University of Medical Sciences. We gratefully thank the Research, Health and Education Deputies of Gonabad University of Medical
Sciences as well as the healthcare professionals affiliated to the study setting. Moreover, we are heartily grateful to all mothers and their family member who participated in the study.

\section{References}

1. Yousefi AA, Moradi K, Safari N, Ghazi SH, Amiri F. The relationship between marital satisfaction with physical problems during pregnancy and associated factors among pregnant women in Khorramabad. Yafte. 2011;13(1):123-31.

2. Zolfaghari M, Asadi Noghabi A. Maternal newborn nursing. 3rd ed. Tehran: Hakim Hidegi Publication; 2011. p,1055.

3. Solchany JE. Promoting maternal mental health during pregnancy: Theory, practice and intervention. Washington: Ncastavenuw Publication; 2003.

4. Bastani F, Heidarnia A, Kazemnejad A, Kashanian M. Effect of relaxation training based on self-efficacy in mental health of pregnant women. Iran J Psychiatry Clin Psychology. 2007; 12(2):109-16.

5. Mossallanejad L, Ashkani H. Motherhood and mental health. 1st ed. Tehran: Ketab-e-Roshan Publication; 2005.

6. 6. Younesi SJ, Salajegheh A. Body image in fertile and infertile woman. Med J Reproduction Infertility. 2001; 2(8):1421.

7. Memarian R. Application of nursing concepts and theories. 2nd ed. Tehran: Tarbiat Modares University Press; 2011. p. 59.

8. AliAkbarzade Arani Z, Taghavi T, Sharifi N, Noghani F, Faghihzade S, Khariarani M. Effect of education on the social adaptation of mothers of trainable retarded children based on Roy adaptation theory. Feiz J. 2012; 16(2):129-34.

9. Hekari D, Mohammadzade R. The assessment of adaptation rate of coronary artery disease female patients according to quadruple aspects of physiologic, self perception, role playing and independence/dependence in Tabriz Investigation, 2005-2006. J Azad Univ of Med sci. 2006; 18(3):187-93.

10. Hennessy-Harstad EB. Empowering adolescents with asthma to take control through adaptation. J Pediatric Health Care. 1999; 13:273-7.

11. Bakan G, Akyol AD. Theory guided intervention for adaptation to heart failure. J Advanced Nursing. 2008; 61(6):596-608.

12. Asgarpoor AF, Amini Z, Zeraati A, Esmaeeli H. Effect of care plan based on Roy adaptation model on fatigue in hemodialysis patients. J Mashhad Med Univ of Sci. 2011; 1(1):77-90.

13. Pour AM, Najafi S, Zadeh JT, Zadeh FM. The effect of intervention based on Roy adaptation model on personal self-concept in primi-gravida women. J Sabzevar Univ Med Sci. 2016; 22(6):999-1007.

14. Nakamura Y, Yoshizawa T, Atogami F. Assessments of maternal psychosocial adaptation for pre-labor hospitalized pregnant women in Japan. Women's Health Nursing, To- 
hoku University Graduate School of Medicine, Japan. Nurs Reports. 2011; 1(9):35-9.

15. Kiehl EM, White MA. Maternal adaptation during child bearing in Norway, Sweden and the United States. Scandinavian J Caring Sci. 2003; 17:96-103.

16. Salari M, Nia ZK, Davachi A, Zoladl M, Babaei Gh R. Effect of education on coping strategies of mothers who have educable mentally retarded children. Armaghan-e-danesh J. 2001; 6(23):1.

17. Barlow JH, Powell LA, Gilchrist M, Fotiadou M. The effectiveness of the training and support program for parents of children with disabilities: a randomized controlled trial. J Psychosomatic Research. 2008; 64(1):55-62.

18. Sercekus P, Mete S. Effects of antenatal education on maternal prenatal and postpartum adaptation. J Advanced Nursing. 2010; 66(5):999-1010.

19. Malekpoor M, Farahani H, Aghaei A, Bahrami A. Effect life skill education on decrease stress in mothers of mental retardation and usual children. Research Except Child. 2006; 20(2):661-76.

20. Mangeli M, Ramezani T, Mangeli S. The effect of educating about common changes in pregnancy period and the way to cope with them on marital satisfaction of pregnant women. Iran J of Med Education. 2008; 8(2):305-16.

21. Hamilton-Dodd C, Kawamoto T, Clark F, Burke JP, Fanchiang SP. The effects of a maternal preparation program on mother-infant pairs: a pilot study. The American J Occupational Therapy. 1989; 43:513-21.

22. Samarel N, Tulman L, Fawcett J. Effects of two types of social support and education on adaptation to early-stage breast cancer. Research Nursing Health. 2002; 25:459-70.

23. Sadegh Nejad M, Vanaki Z, Memarian R. Effect of care plan based on the psychological adaptation of patients with type II diabetes. Evidence Based Care. 2011; 1(1):6-8.

24. Whittemore R, Jaser S, Guo J, Grey M. A conceptual model of childhood adaptation to type 1 diabetes. Yale University School of Nursing. Nursing Outlook. 2010; 58:242-51.

25. Ingram L. Roy's adaptation model and accident and emergency nursing. J Accident Emergency Nursing. 1995; 3(3):150-3.

26. Rogers C, Keller C. Roy's adaptation model to promote physical activity among sedentary older adults. Geriatric Nursing. 2009; 30(2):21-6. 